\title{
أثر علاقة السلطة التنفيذية بالسلطة التشريعية على طبيعة النظام السياسي الجزائري
}

The impact of the executive power's relationship with the legislative power on the nature of the Algerian political system

تاريخ الاستلام : 2019/04/12 ؛ تاريخ القبول : 2019/05/30

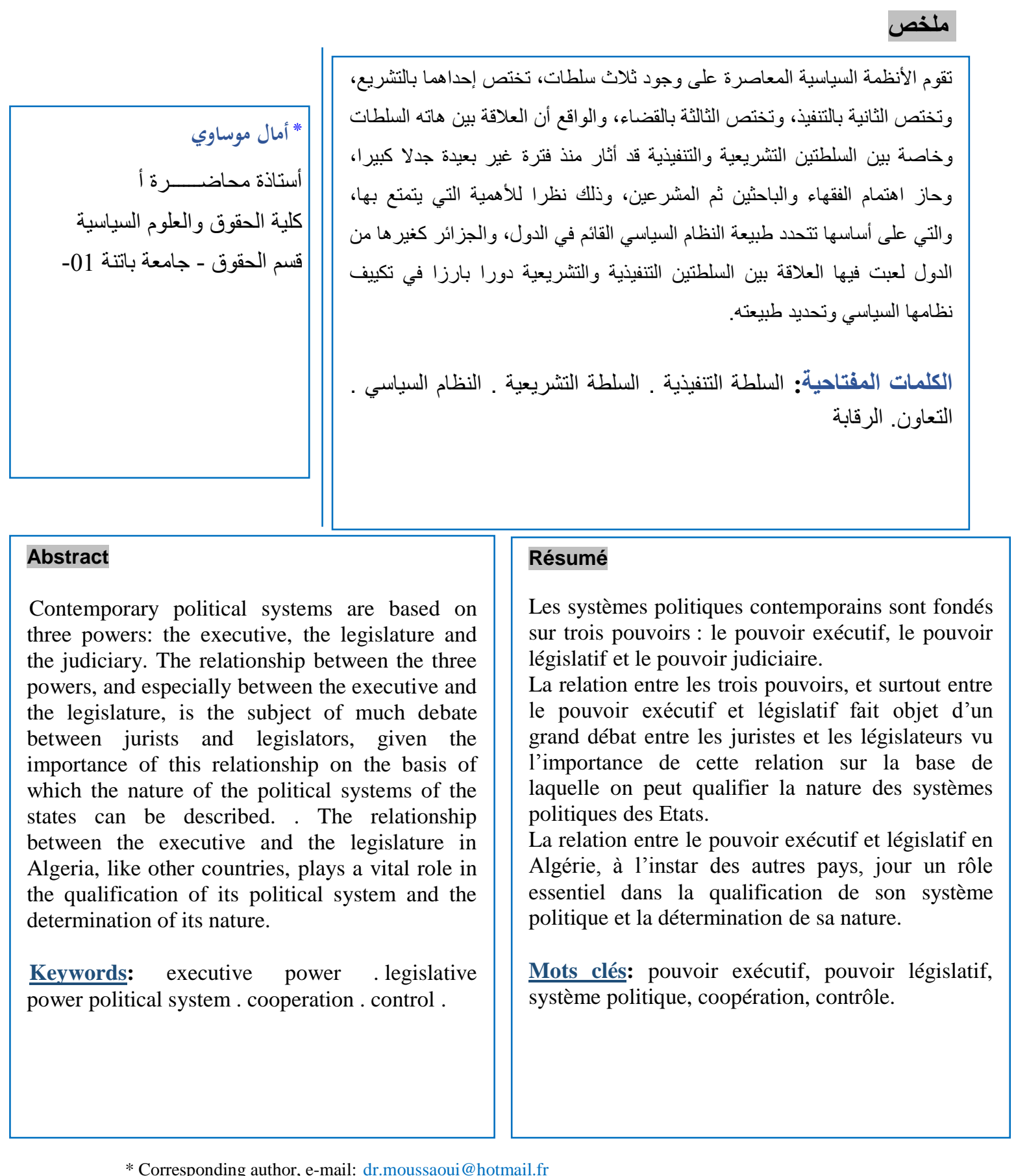

* Corresponding author, e-mail: dr.moussaoui@hotmail.fr 
لقد عرف العالم العربي منذ بداية هذا القرن تطورات سياسية جوهرية، مقدمة:

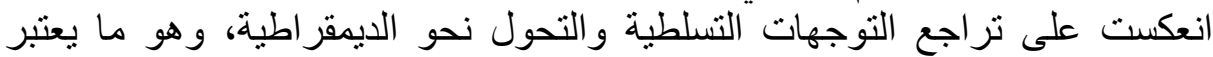
بمثابة ظاهرة ملموسة في در استة التوات النظم السياسية العربية.

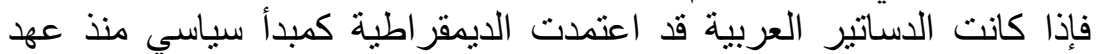

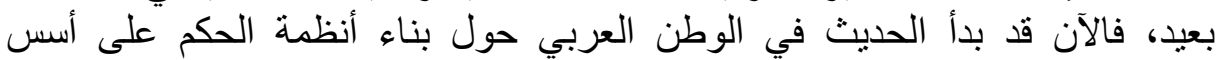

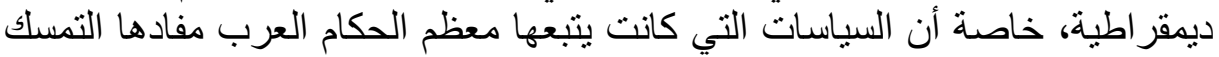

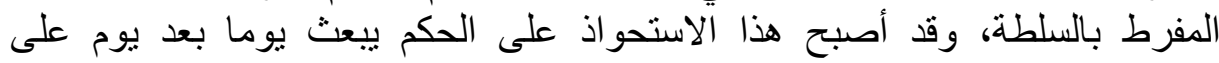

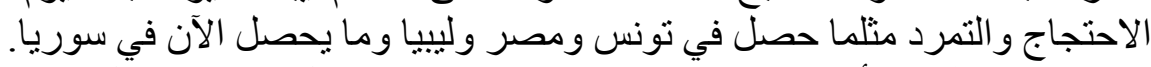

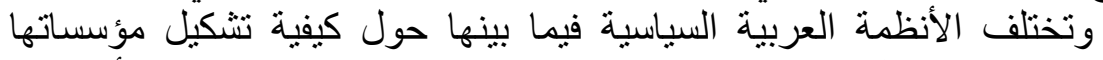

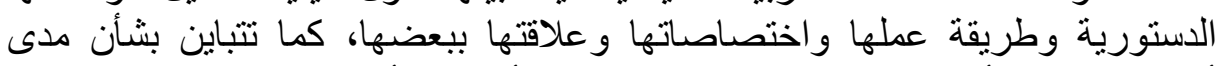

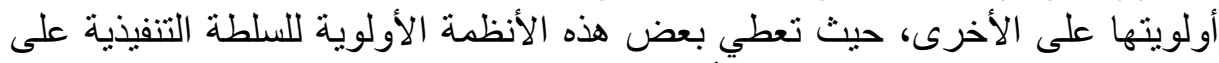

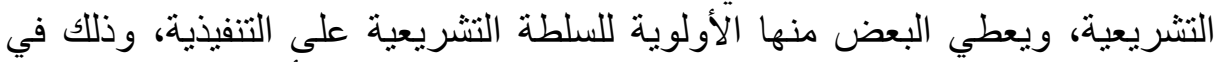

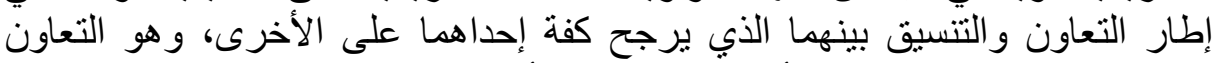

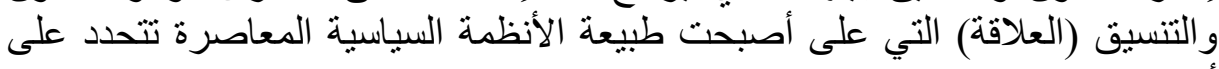

و عليه فإن الإشكالية التي ارتأينا معالجتها ضمن هذه الورثة البحثية يمكن

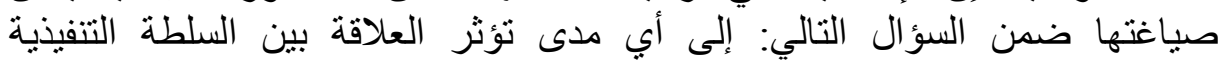

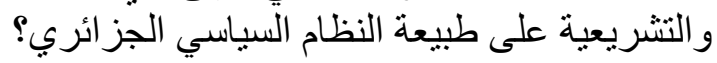
و هي الإشكالية التي تستوجة النظام الإجابة عنها التطرق لنثلاثة محاور رئيسية هي: ـ مفهوم السلطة التنفيذية و السلطة التشئة التشريعية. ـ تأثثر هيمنة السلطة التنفيذي على السلة التئلة التشريعية.

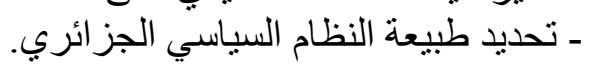

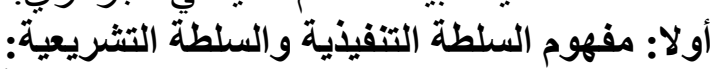

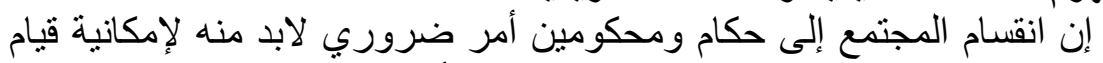

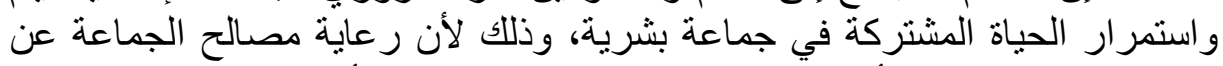
طريق العمل المشترك لأبنائها يحتاج إلى قيادة موجهة واعة واعية تأمر فتطاع.

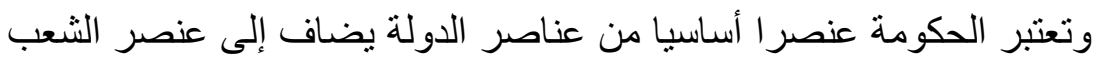
و الإقليم و الحكومة بهيئاتها التشريعية و التنفيذية و القضائية تتكون من أفر اد هم الحكام (1)،

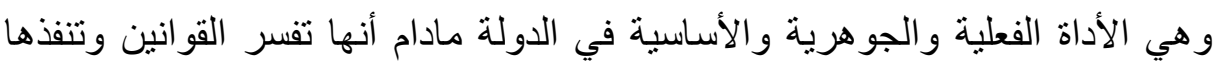
وتمنع الاعتداء على الحقوق. وقد انتشر الأخذ بنظام التقسيم الثلاثي لسلطات الدولة، بحيث تقوم هيئة بسن التشريع و هي السلطة التشريعية، وتتولى أخرى وظيفة التنفيذ وهي السلطة التنفيذية، وتختص الثالثة بالفصل في المناز عات و هي السلطة القضائية.

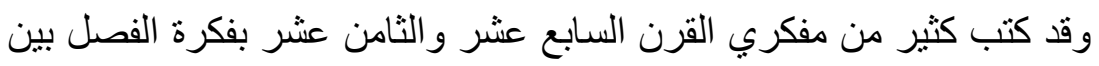

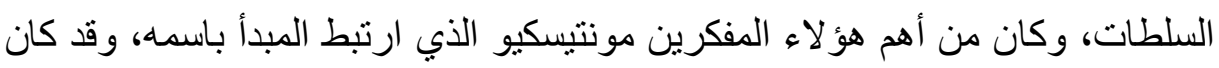

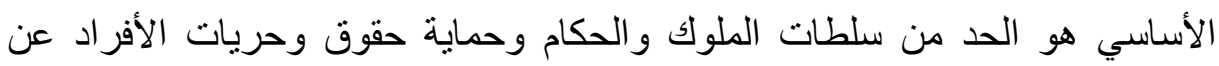

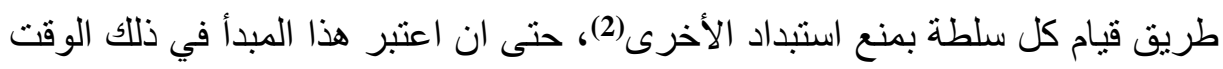

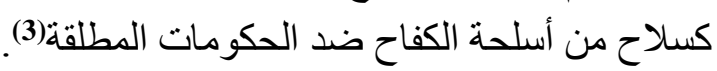
تلك التي كانت تعمد إلى تركيز جميع السلطات بين يديها ووسيلة للتخلص من 
استبداد الملوك وسلطتهم المطلقة، وقد وجد هذا المبدأ صدى كبير لاى رجال الثورة

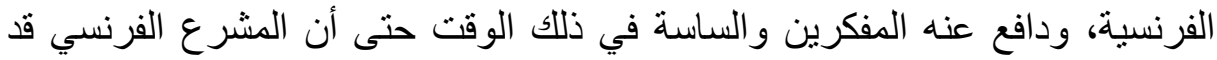

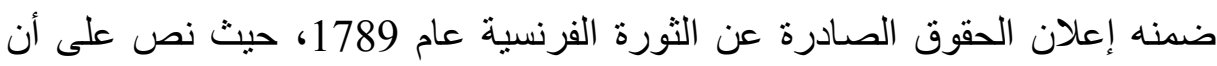
״كل جماعة سياسية لا تضمن حقوق الأفراد و لا تفصل بين السلطات لا دستور لهاهي. إن مبدأ الفصل بين السلطات يؤدي إلى تحقيق شرعية الدولة، ذلك الكافئ أن تركيز سلطات الدولة التشريعية والتنفيذية في قبضة يد واحدة من شانه أن يخلع عن القانون

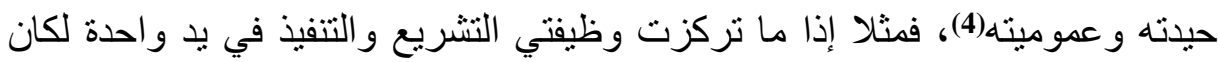

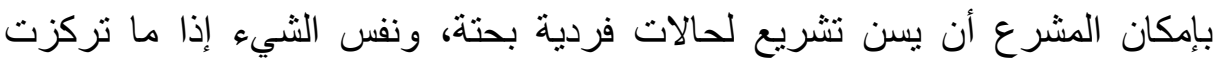

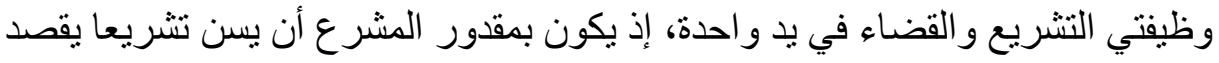

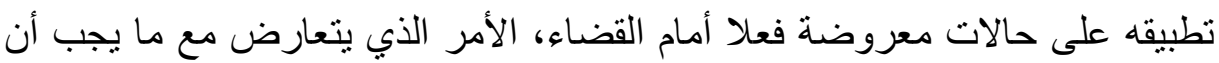

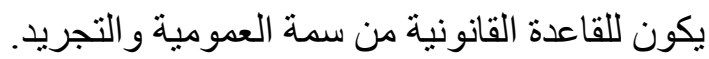

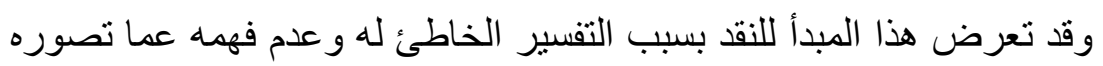
مونتيسكيو، إذ رأى البعض أنه يقضي بوجوب الفصل التام والمطلق بين السلطات الثلاث، فاعتبروه مبدأ جامد، أما المبدأ كما تصوره أنها مونتيكسيو يمكن تطبيقه بمرونة،

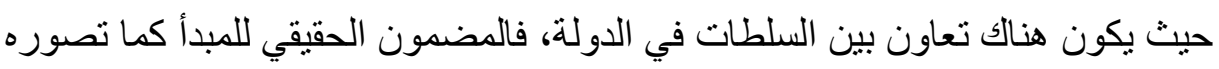

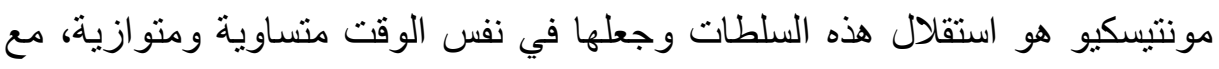

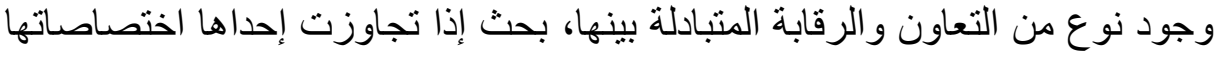
أمكن لغير ها أن تردعها عند حدود التعاون والرنا. و المقصود بالتعاون هنا أن يكون بين السلطتين ذات الطابع الحكومي أي

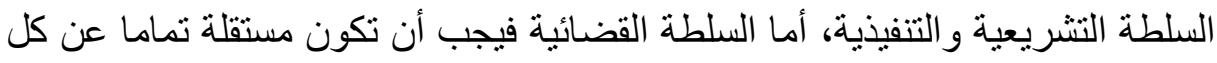
من الحكام و المحكومين على وجها يحقق العدالة.

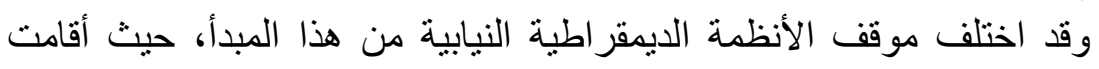

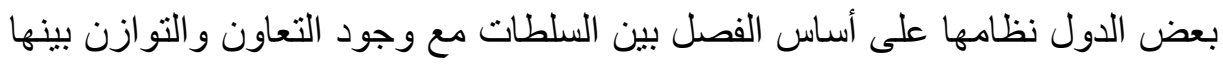

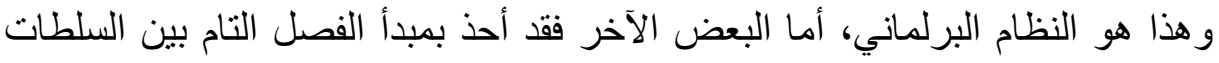

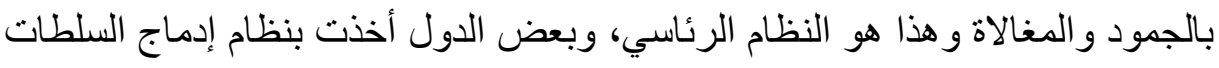

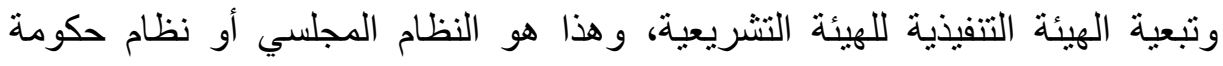

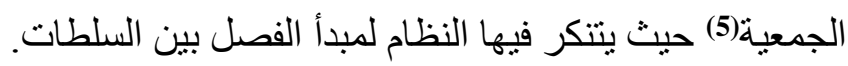

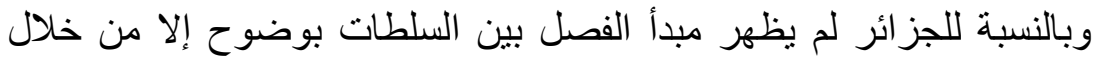

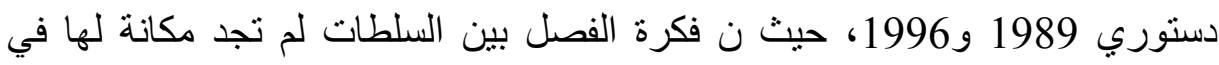

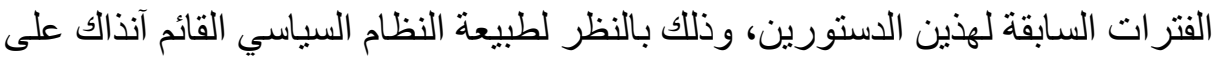

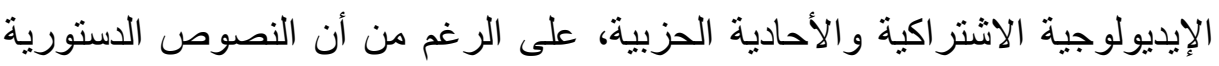

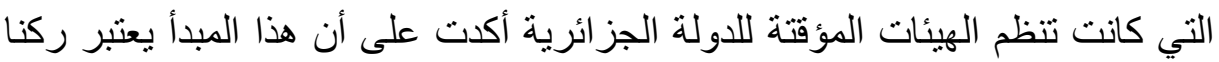

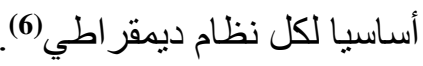

أ- مفهوم السلطة التنفيذية:

هي السلطة التي تعمل على وضع التشريعات والسياسات العامة التي تحظى التهلئل

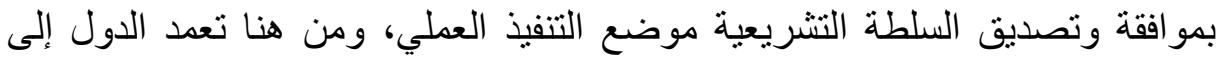
توفير كافة الإمكانيات والقدرات التي تلزم السلطة التنفيذية في أدائها لمسؤوليتها 
المتزايدة خاصة وقد اتسعت دائرة التشريعات الاجتماعية والاقتصادية تحت ضغط

الإيديولوجيات السياسة المعاصرة التي تحث الدولة بقوة على اقتحام كافة المجالات(7).

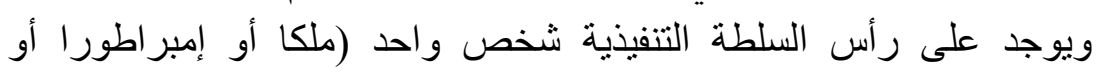

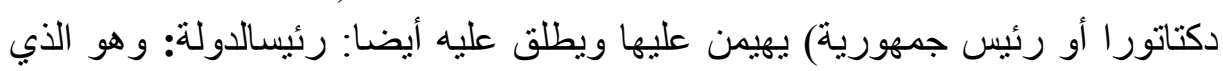

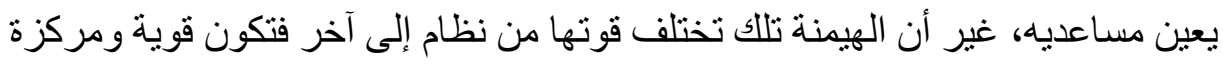

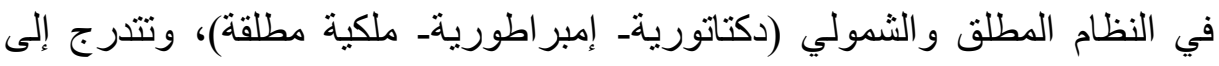
النظام الرئاسي حيث يهيمن رئيس الدولة على السلطة التنفيذية دون منازع، إلى النظام

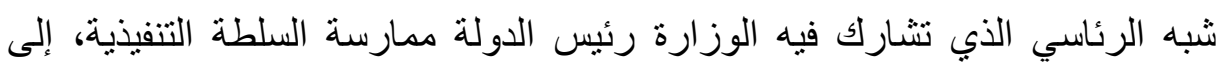

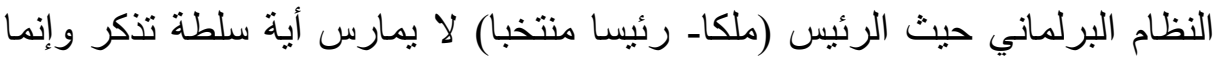

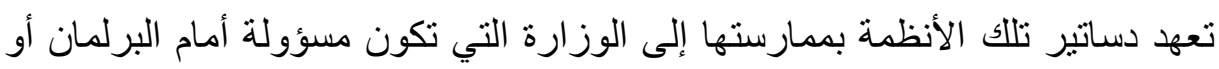

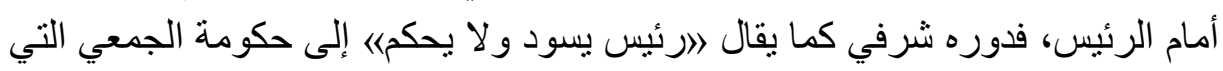

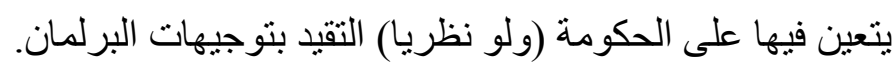

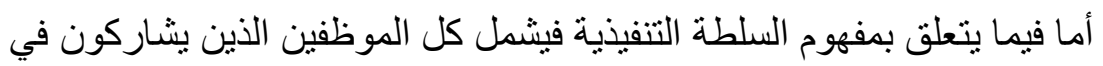
تنفيذ القوانين بدءا من رئيس الدولة حتى آخر موظف في السلك الإداري للإولة فئلة

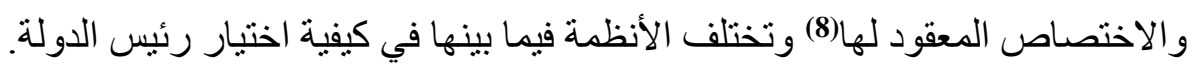

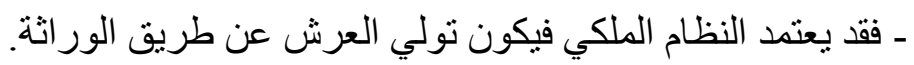

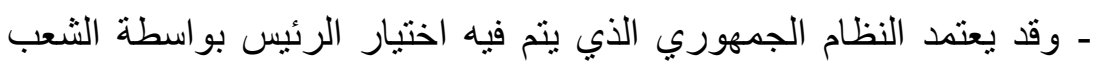

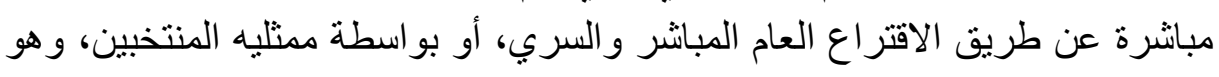

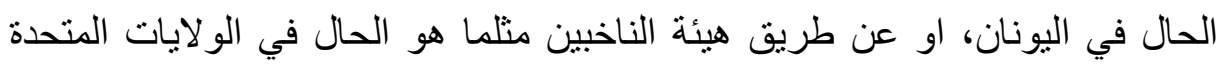
الأمريكية.

$$
\text { ـ أما في النظام الدكتاتوري فتجتمع كل السلطات في يده(9). }
$$

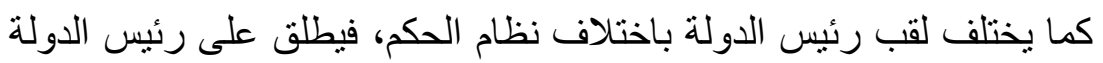

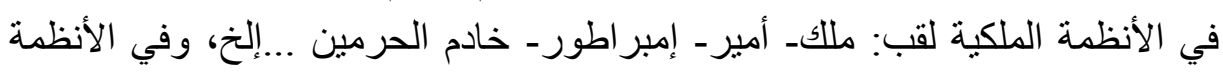

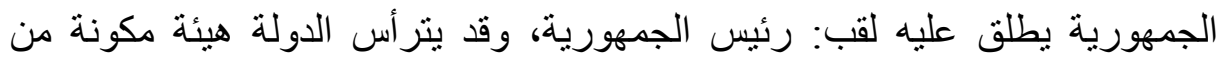

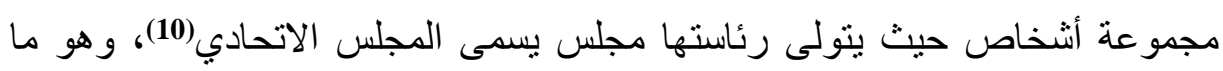
أخذت به سويسرا، حيث يتولى السلطة التتفيذية المركزية المجلس الاتحادي الذي يتكي لئكون

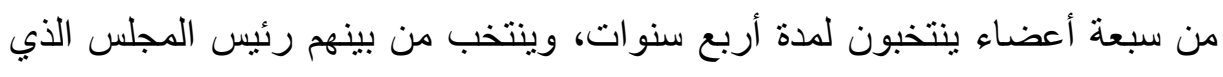

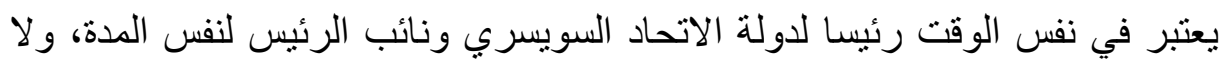

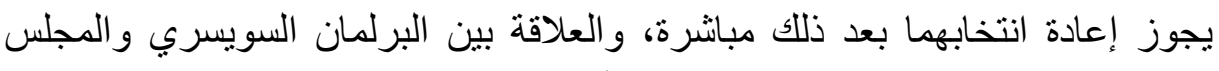

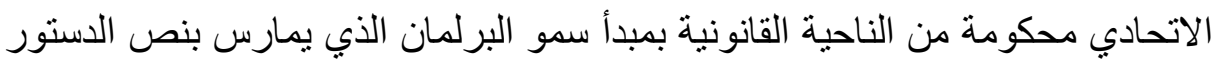

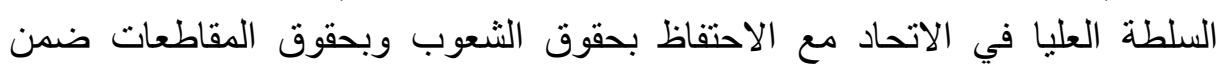

$$
\text { الحدود المنصوص عليها في الدستور (11). }
$$

ب- مفهوم السلطة التشريعية: هي السلطة التي يناط بها وظيفة التشريع وسن القوانين والتصديق على التى التي

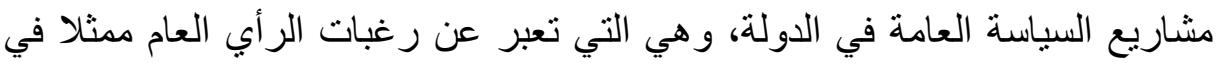


مختلف اتجاهاته ورغباته ودو افعه ومصالحه.

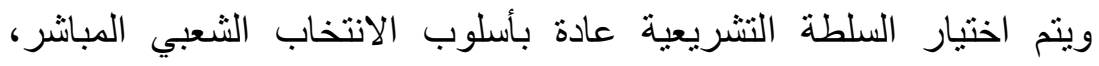

فللسلطة التشريعية مكانة خاصة ومتميزة بالنسبة إلى السلطتين التنفيذية والقضائية،

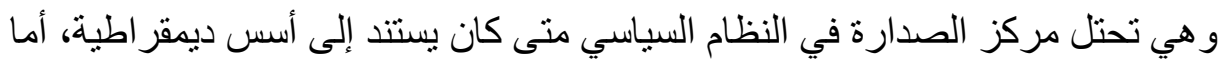
في النظم الدكتاتورية حيث تكون الإرادة الفردية بمثابة القوة المهيمنة على النظام

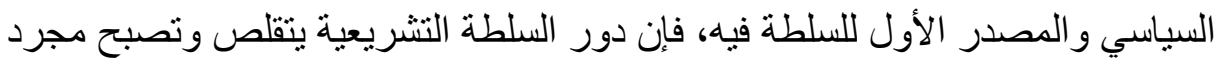

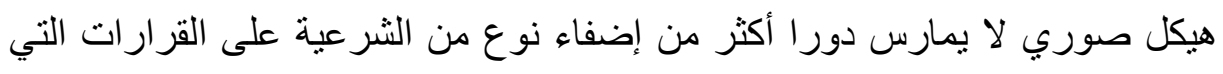

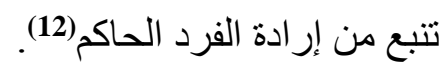
وتختلف الأنظمة السياسية فيما بينها من حيث تكوين برلمانها، فقد يتكون من مجلس و احد أو من مجلسين يخص بالوظيفة التشريعي. و البرلمان هو تلك الهيئة السياسة المشكلة من مجلس أو مجلة مجلسين يضم كل

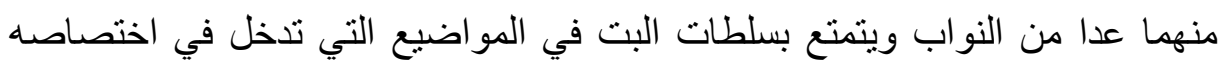
وأهمها التشريع و المر اقبة(13). ويسمى المجلس الأول بالغة الأولى أو مجلس النواب أو الجمعية الوطنية أو مجلس العموم أو مجلس الثعب. أما المجلس الثاني فيسمى بالغرفة الثانية أو المجلس الأعلى أو مجلس الثيوخ أو مجلس الأعيانأو مجلس اللوردات أو المجلس الفدر الي أو مجلس الأمة.

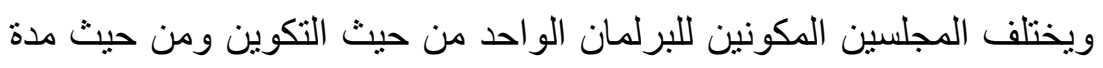

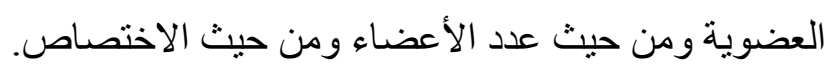
فمن حيث التكوين يختلف المجلس الأول عن المجلس الثاني، حيث الأن أن الأول

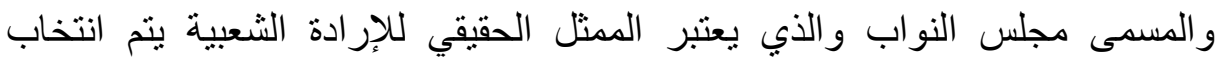

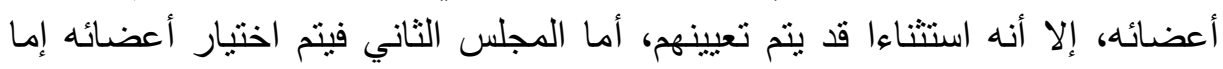

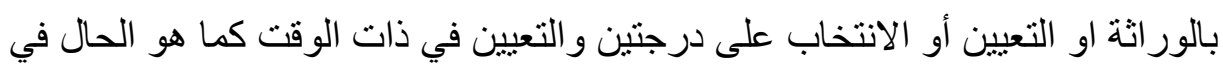

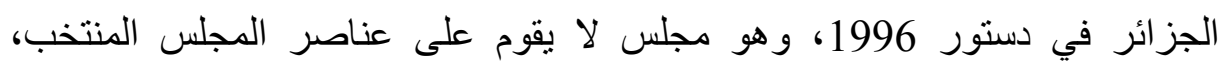
وبالنسبة للاختلاف في عمر الناخب و النائب فالمجلس المنتخب يكون ناخبوه ولأبو وأعضاؤه أقل سنا من ناخبي وأعضاء المجلس الثاني، و الغرض من ذلك هو التوفيق بين الثباب

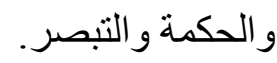
أما مدة العضوية فهي أقصر في المجلس المنتخب حتى يتمكن الثعب من

مر اقبة ممنليه باستمر ار، على خلاف المجلس الثاني الذي يكون التجديد جزئيا فيه(14).

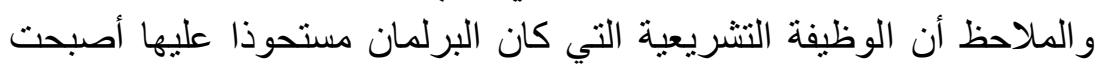
ممارستها أيضا من قبل المؤسسة التنفيذية سواء عن طريق تفويض الته أو أنها مستمدة ومقررة في الدستور و إن كانت لمدة محددة سو اء في الحالات العادية أو غير العادية.

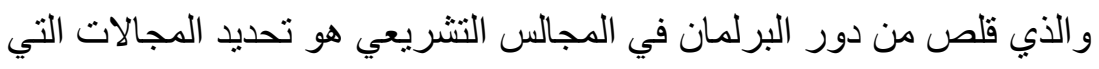

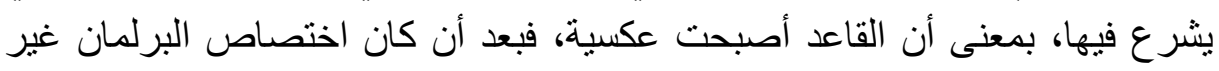

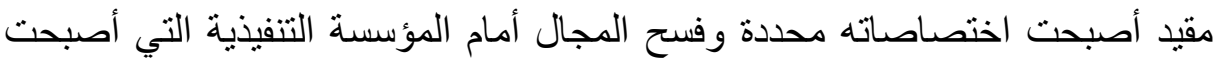

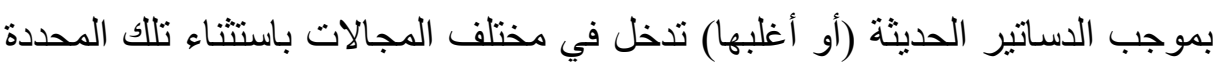
و المخصصة للبرلمان و التي يمكن أن تثاركه المؤسسة التنفيذية فيها. 
و إلى جانب كون الاختصاص التشريعي للبرلمان محددا، فإنه مقيد أيضا

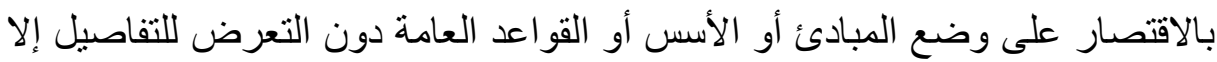

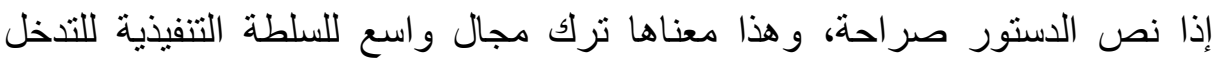
بواسطة التنظيم (المر اسيم أو القرارات) لشرح كيفيات تنفيذ أو تطبيق القانون وتفسير ما هو غامض فيها، مما بضعف من مكانة البرلمان أمام الحكومة (15). ثانيا: تأثير هيمنة السلطة التنفيذية على السلطة التشريعية:

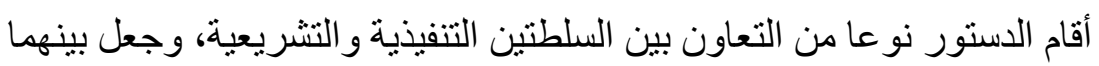

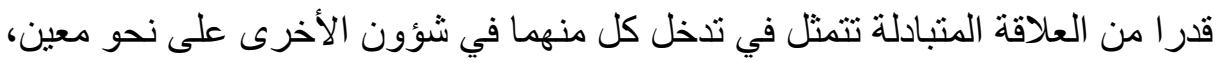

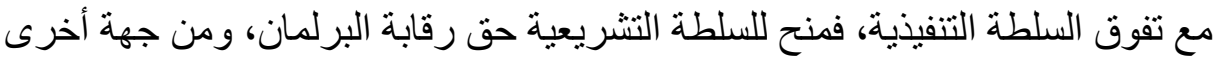
منح للسلطة التنفيذية حق التدخل في بعض أعمال واختصاصات السلطة التشريعية، وفقا لما سنوضحه ضمن الآتي: أ- مظاهر رقابة البرلمان للسلطة التنفيذية:

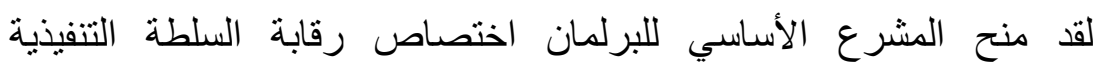

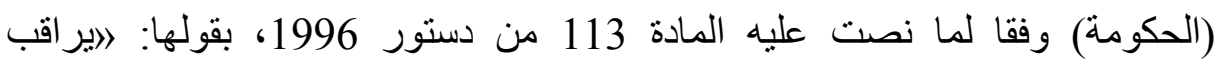

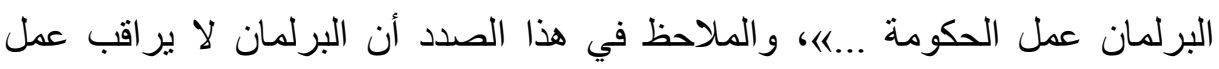

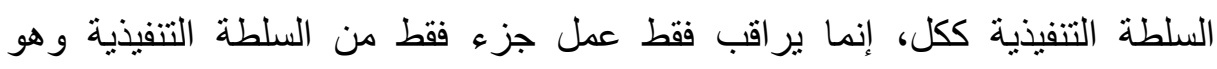
الحكومة، وذلك وفقا للآليات التي منحها إياه الدستور، و المتمثلة أساسا فيما يلي: 01- مناقشة مخطط عمل الحكومة: مخطط عمل الحكومة هو المخطط الذي يتضمن

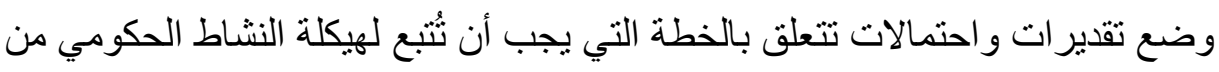

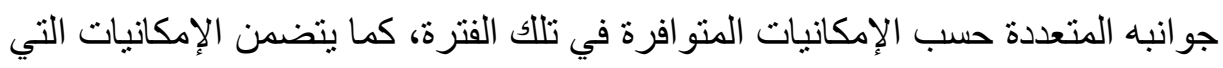

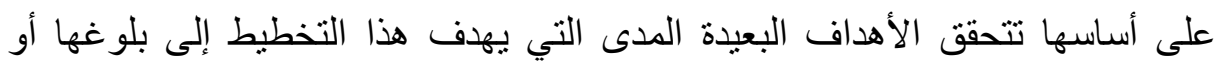

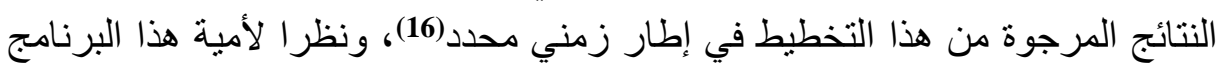

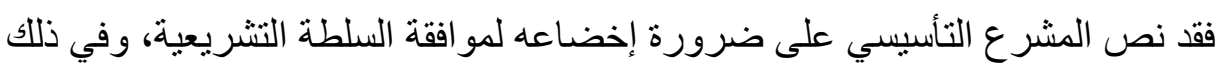
أورد المشرع الجزائري على مجمو عة من النصوص التئي على أهمها:

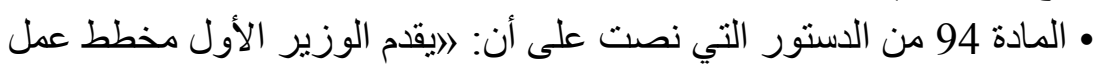

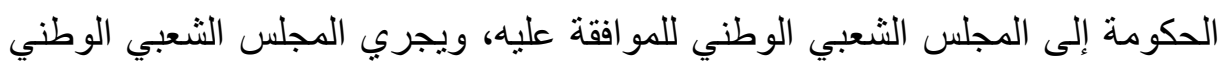
لهذا الغرض مناقثنة عامة. - ويمكن للوزير الأولأن يكيف مخطط العمل هذا، على ضوء هذه هذه المناقثة

$$
\text { بالتشاور مع رئيس الجمهورية. }
$$

- يقدم الوزير الأول عرضا حول مخطط عمل الحكومةلمجلس الأمة مثلما

$$
\text { و افق عليه المجلس الثعبي الوطني. }
$$

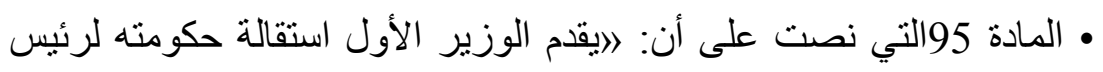

الجمهورية في حالة عدم مو افقة المجلس الثعبي الوطني على مخطط عمل الحكومة.

$$
\text { - يعين رئيس الجمهورية من جديد وزير ا أول حسب الكيفيات نفسهابه. }
$$

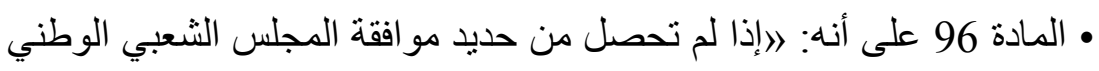


ينحل وجوباءا.

وبالتالي فإن بقاء الحكومة ابتداءاو انتهاءا مرهون بموافقة المجلس الثُبي

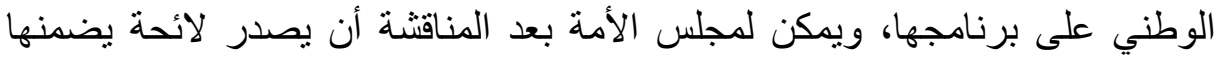

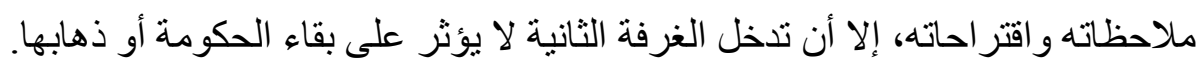

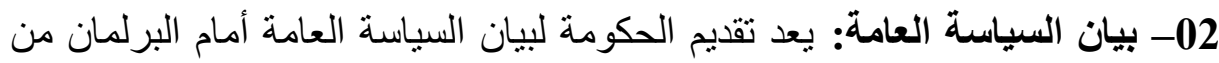

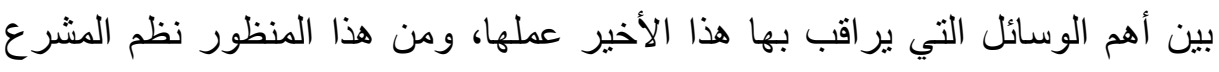

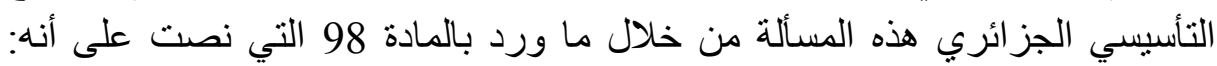

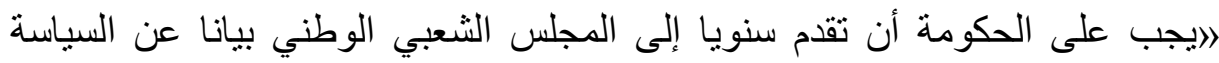

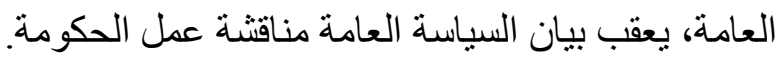

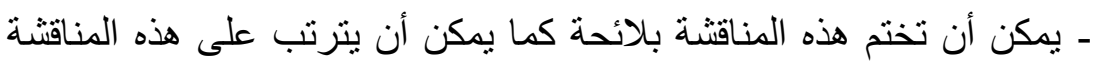

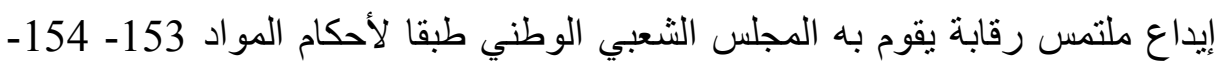
155

ـ للوزير الأولأن يطلب من المجلس الشعبي الوطني تصويتا بالثقة، وفي حالة

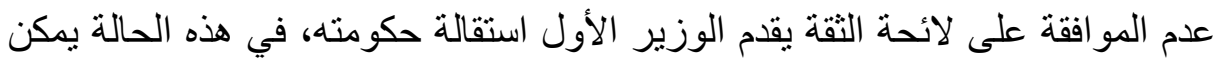
لرئيس الجمهورية أن يلجأ قبل قبول الاستقالة إلى أحكام المادة 147 أدناه. - يمكن للحكومة أن تقدم إلى مجلس الأمة بيانا عن السياسة العامةً).

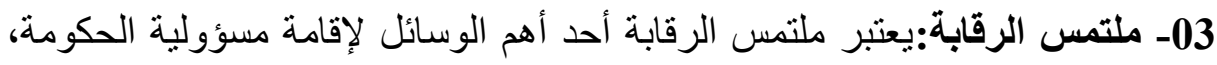

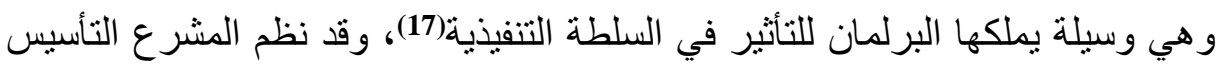

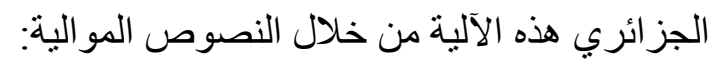

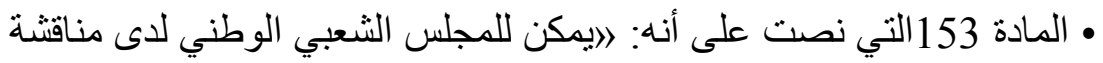

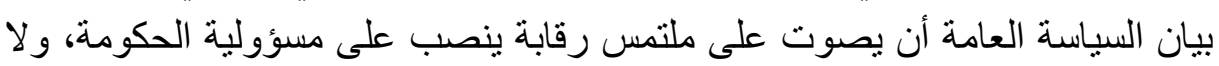
يقبل خذا الملتمس إلا إذا وقعه سبه (7/1) عدد النواب على على الأقلىها.

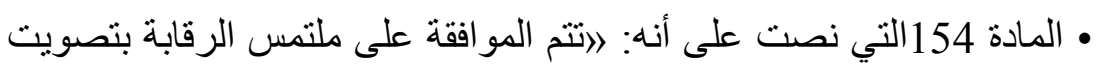

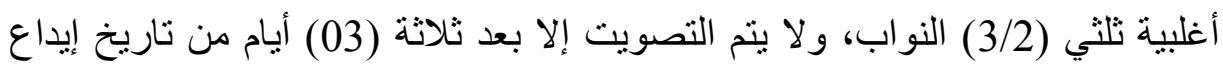
ملتمس الرقابة)،.

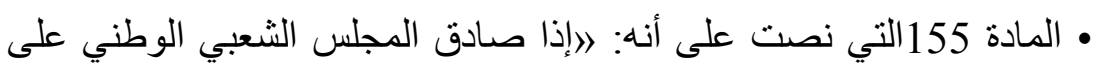
ملتمس الرقابة يقدم الوزير الأول استقالة حكومته إلى رئيس الجمهوريةها.

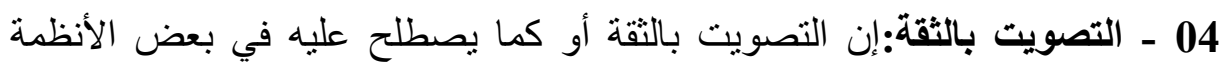

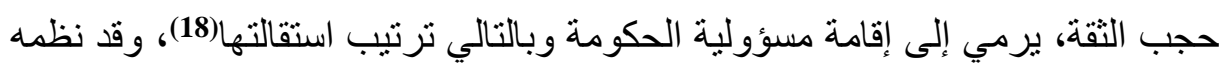

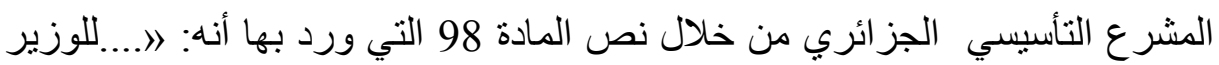
الأول أن يطلب من المجلس الشعبي الوطني تصوينا بالتقة، وفي حالة عدم المو افقة على التى لائحة التقة يقدم الوزير الأول استقالة حكومتهاهـ. 05 - الاستجواب:يعد الاستجواب أيضا من بين الآليات الممنوحة للبرلمان في إطار

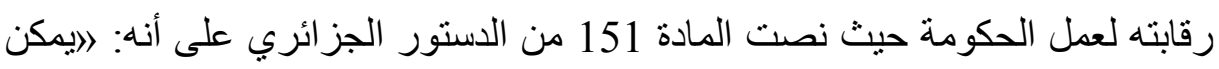

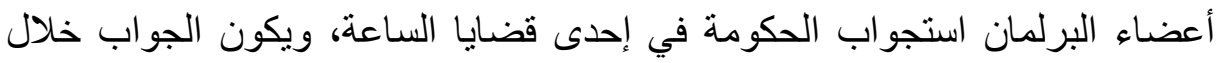

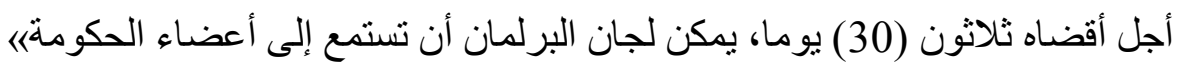

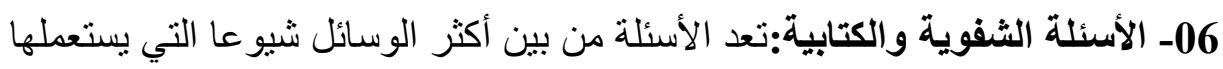


البرلمان في رقابته لمل الحكومة، والتي يهدف من خلال طرحها إلى معرفة مسألة ما

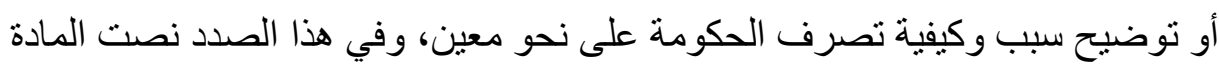

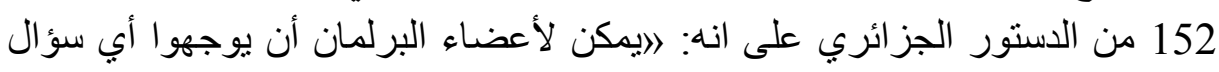

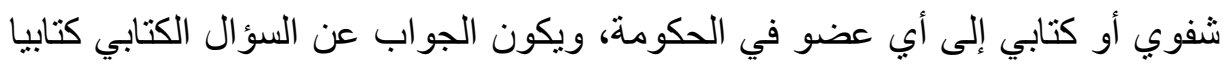

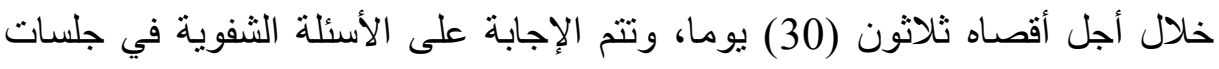

- بالنسبة للأسئلة الثفوية، يجب ألا يتعدى أجل الجو اب ثلاثثين (3 يوما). المجلس.

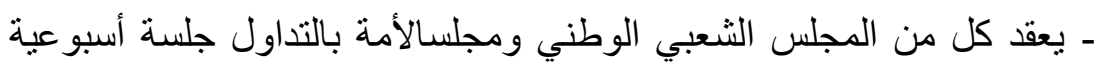

تخصص لأجوبة الحكومة على الأسئلة الثفوية للنواب وأعضئ أعضاء مجلس الأمة.

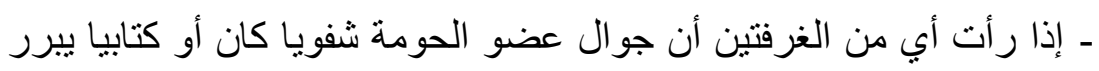

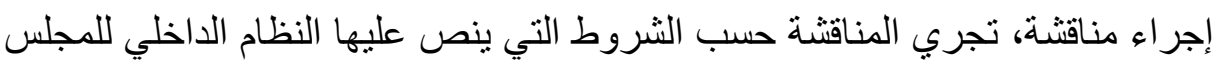
الثعبي الوطني ومجلس الأمة. تنشر الأسئلة والأجوبة طبقا للشروط التئي يخضع لها نشر محاضر مناقثات البرلمانها. 07- لجان التحقيق:منح المشرع الأساسي لكلا غرفتي البرلمان إنشاء لجان تحقيق في

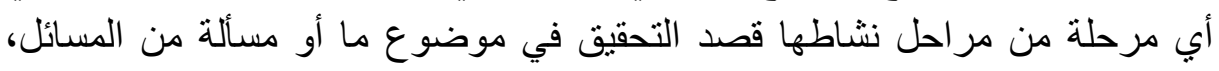

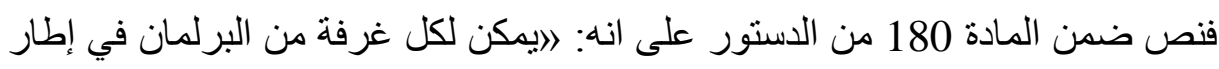

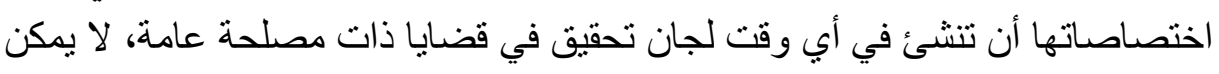

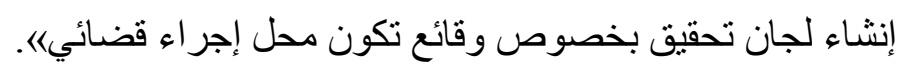

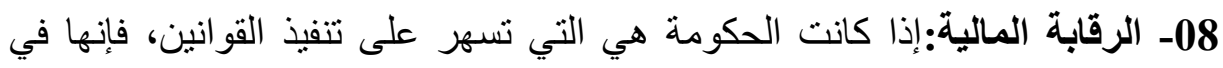

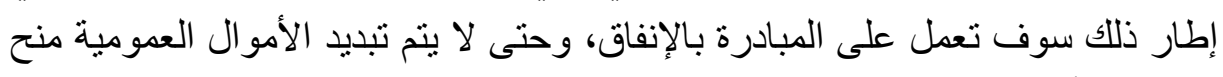

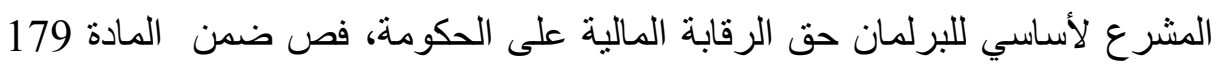

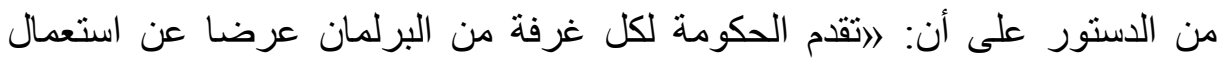

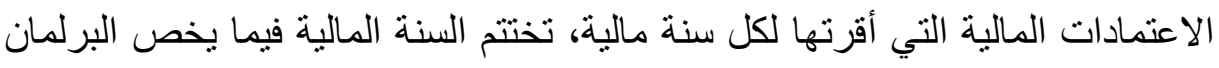

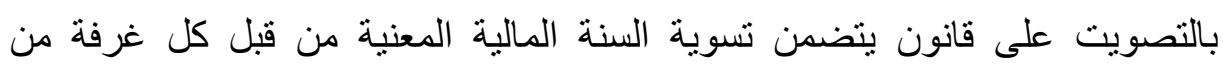
البرلمانها.

ب- هيمنة السلطة التنفيذية على السلطة التشريعية:

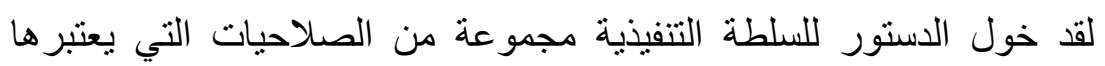

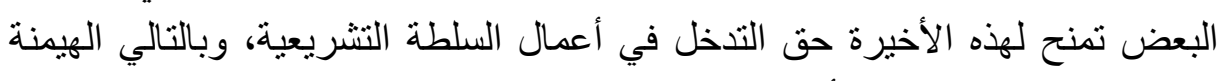
عليها، وقد منح المشرع التأسيس الجزائري لرئيس الجمهورية صلئ صلاحيات كثيرة تمكنه

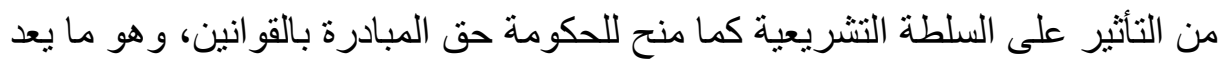
تدخلا من السلطة التنفيذية في عمل السلطة التشريعية على النحو الذي سنصلئل التصله أدناه.

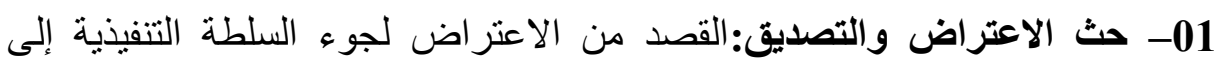

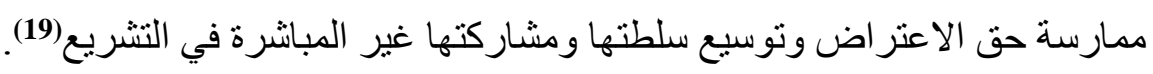

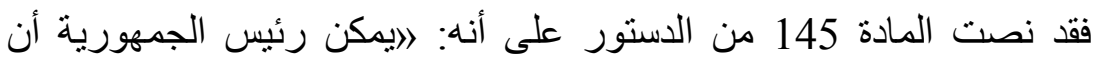
يطلب إجر اء مداولة ثانية في قانون تم التصويت عليه في غضون التهن الثلاثين يوما المو الية 
لتاريخ إقراره، وفي هذه الحالة لا يتم إقرار القانون إلا بأغلبية ثلثي (3/2) أعضاء المجلس الثعبي الوطني وأعضاء مجلس الأمةنه.

02- حق حل المجلس الثعبي الوطني:حل البرلمان وسيلة من أقوى الوسائل التي

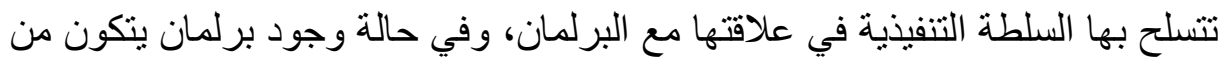

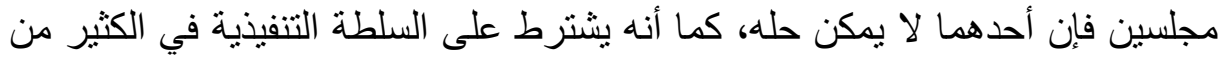

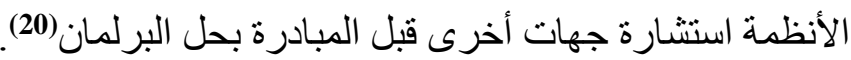
و هو إجراء ينطبق على المجلس الثعبي الوطني دون مجلس الأمة، وقد يكون التبل

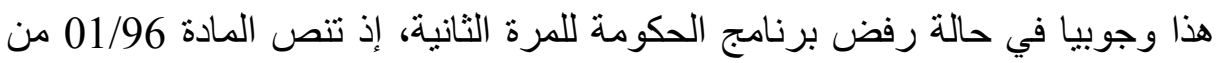
الاستور على أنه: 》إذا لم تحصل من جديد موافقة المجلس الثعبي الوطني ينحل وجوباه.

ويمكن لرئيس الجمهورية أن يقرر حل المجلس أو إجراء انتخابات تشريعية

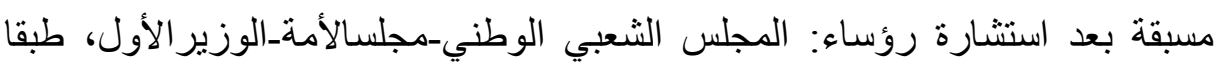

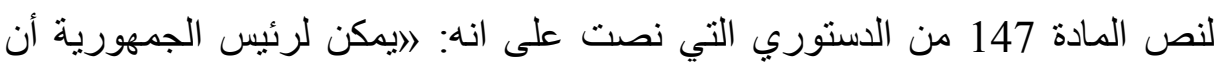

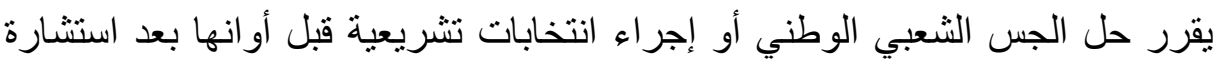

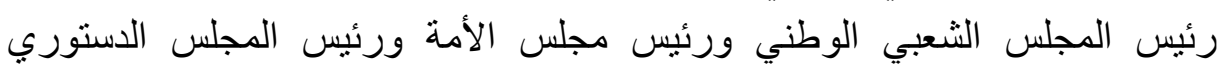

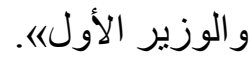

وأهم هدف يمكن تصوره من وراء حل المجلس الثعبي الوطني من طرف رئيس الجمهورية هو تنظيم انتخابات تتريعية من شانها أن تجلب أغلبية نيابية مساندة ولهن لرئيس الجمهورية(21) الجمهورية 03 - حق اللجوء للاستفتاء: يعتبر هذا الأخير وسيلة فعالة يلجأ إليها الحكام لاستشارة الثعب مباشرة في الأمور التي تخص الدولة، وهو صورة صورة من صور ممارسة السلطة

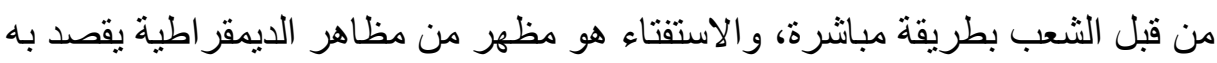

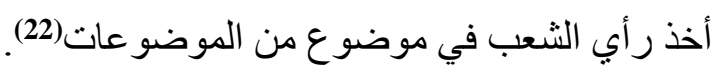

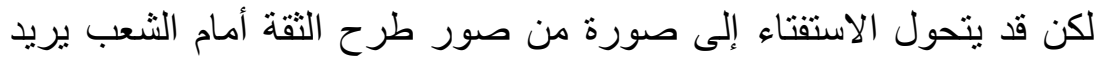

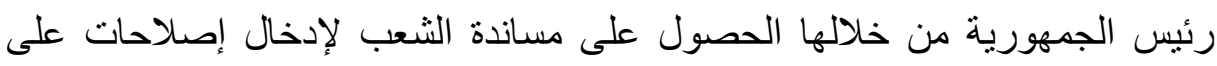

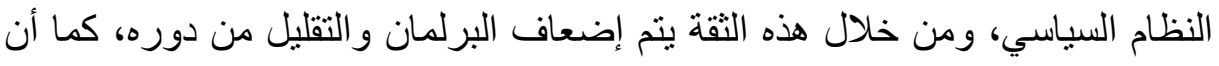
عد تقييد سلطة اللجوء إلى الاستفتاء من شأنه تقوية السلطة التنفيذية في مواجهة السلطة التشريعية(23). إذ تتص في هذا الصدد المادة 91 من الدستور على أنه:لا...يمكن ان يستشير الشعب في كل قضية ذات أهمية وطنية عن طريق الاستفتاء ...٪.

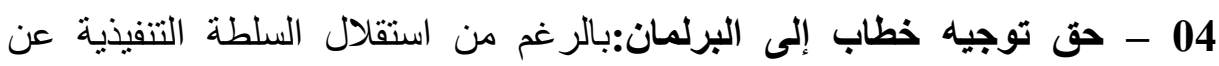

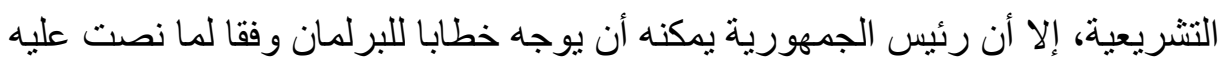

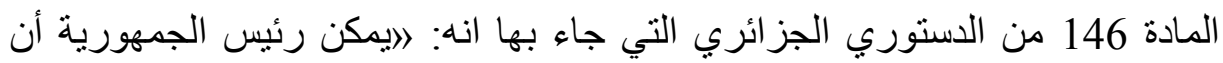
يوجه خطابا إلى البرلمانها. 05 - التشريع عن طريق الأوامر: لقد أعطى الدستور لرئيس الجمهورية الحق في أن

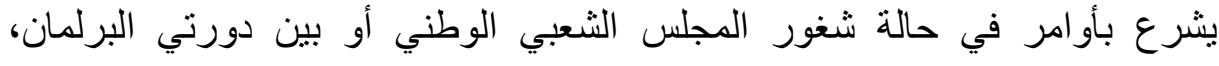

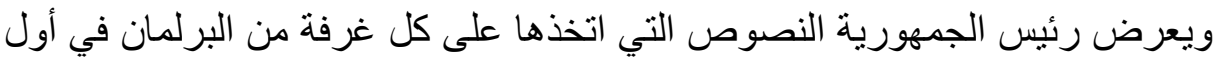


دورة له لتو افق عليها وتعد لاغية الأوامر التي لا يوافق عليها البرلمان(24).

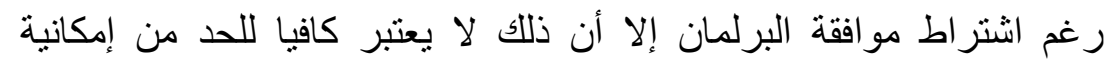

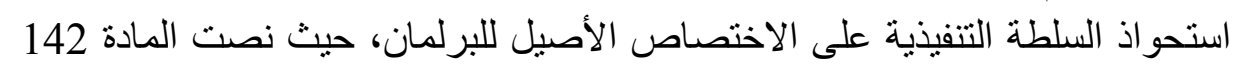

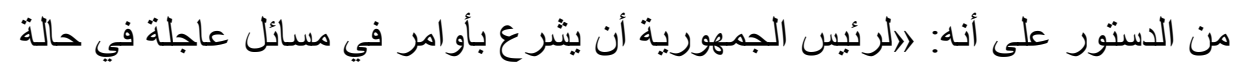

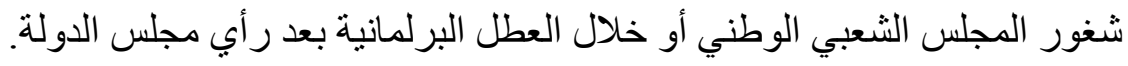

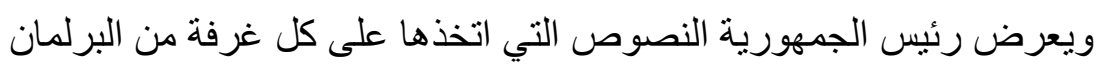

في أول دروة له لتوافق عليها.

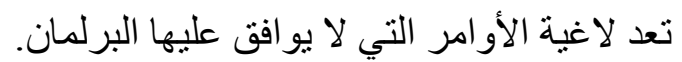

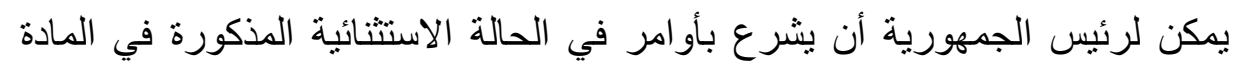

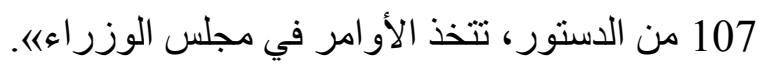

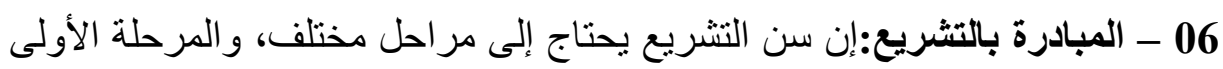

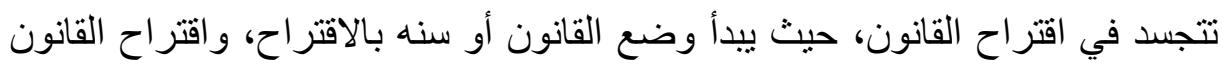

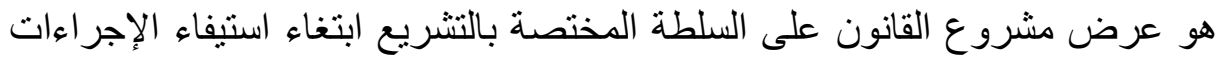
الو اجبة دستوريا لصدور تشريع بهـ(25.

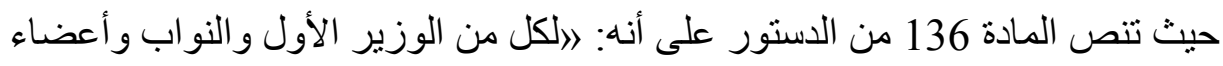
مجلس الأمة حق المبادرة بالقو انين. تكون اقتراحات القوانين قابلة للمناقشة إذا قدمها عشرون (20) (20) نائبا أو الو عشرون (20) عضوا في مجلس الأمة في المسائل المنصوص عليها في المانة المادة 137 أدناهي). 07 - ودعوة البرلمان للانعقاد:بالر غم من أن العمل التشريعي كقاعدة عامة مستقل عن التان

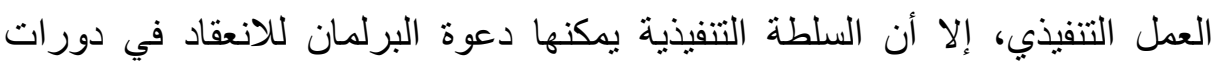

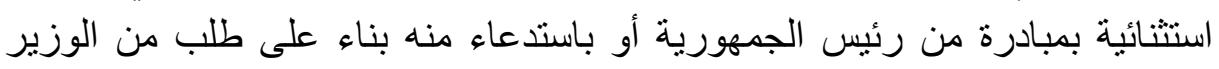

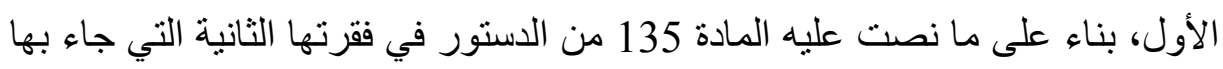

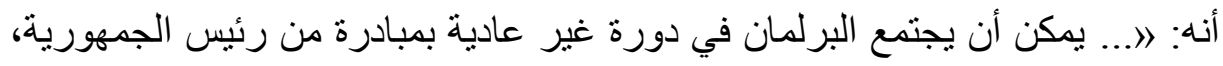

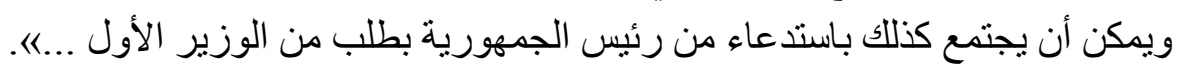

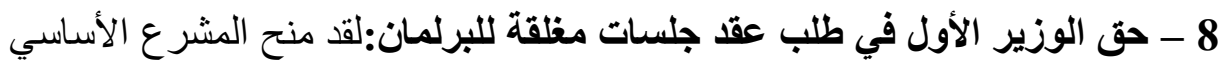

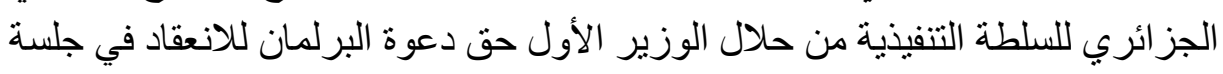

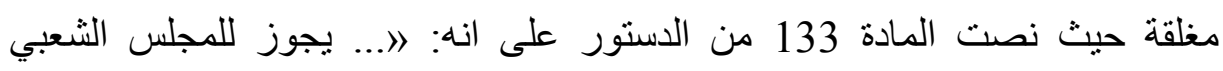

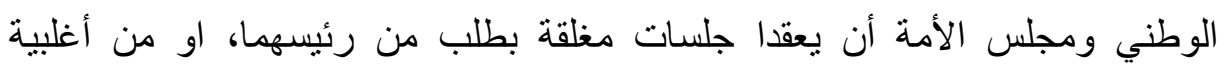

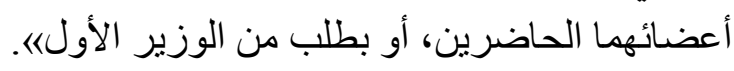

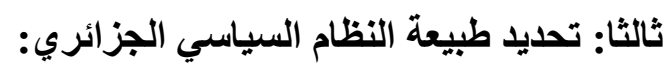

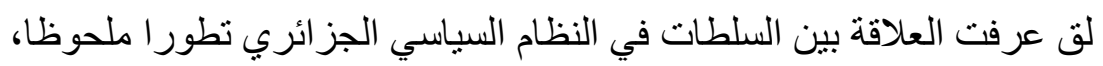

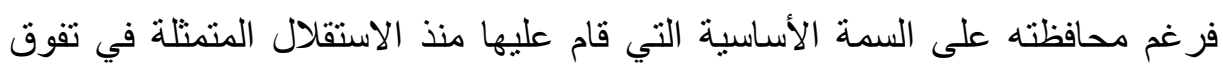

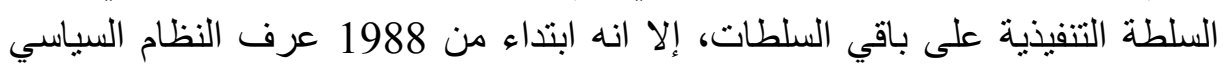

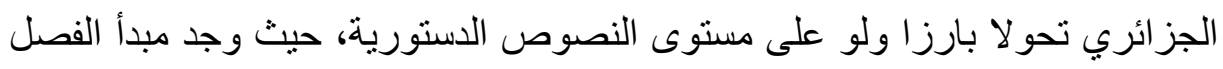
بين السلطات مكانته في دستوري 1989 و و1996 عكس ما كان علئ عليه الوضع في 
دستوري 1963 و1976 حيث كانت وحدة السلطة هي الغالبة، وقد ساهم في تبني هذا التوجه الأحادية الحزبية والتوجه الاشتراكي للدولة آنذاك، وقد كرس دستور 1996

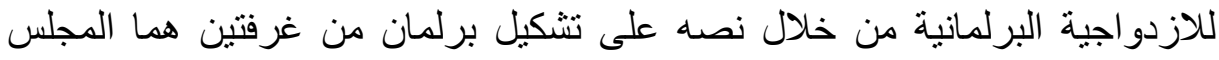

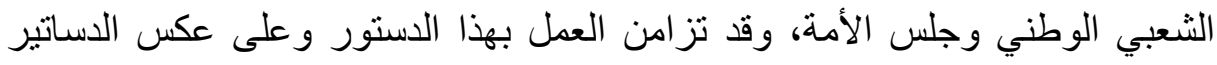

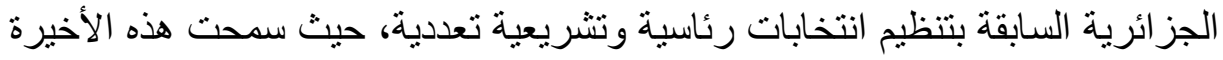

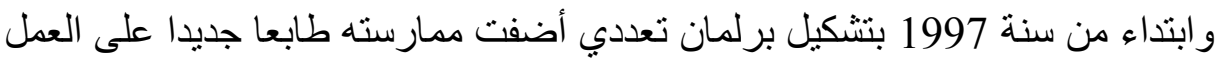

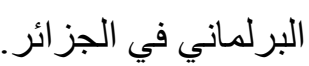

كما ادخلت تعديلات على دستور 1996 استهدفت إعادة تنظيم السلطة التنفيذية

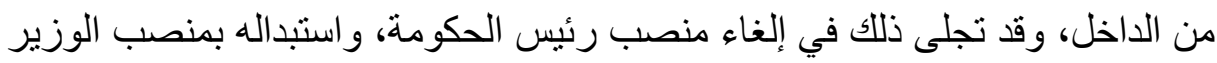
الأول الذي كرسته الممارسة السياسية في الجز ائر منذ الاستقلال(26).

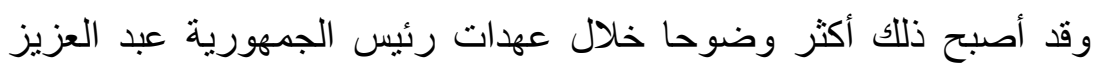
بوتفليقة، ويظهر ذلك جليا من خلال تبني الحكومات المتعاقبة لبرنامجه و التزامها بتنفيذه. وقد نص التعديل الدستوري صر احة على أن مهمة الوزير الأول هي تطبيق

برنامج رئيس الجمهورية وينسق من أجل ذلك عمل الحكومة(27). وقد أبقى التعديل الدستوري لسنة 2008 على السلطة الرقابة للمجلس الشعبي دئي

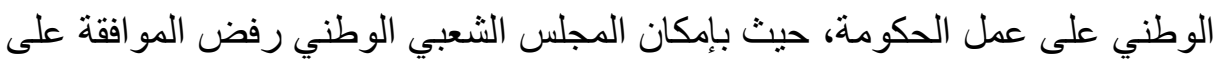
مخطط عمل الحكومة، الأمر الذي يترتب عليه حليه تقديم الوزير الأول لاستقالة حكومته الأله

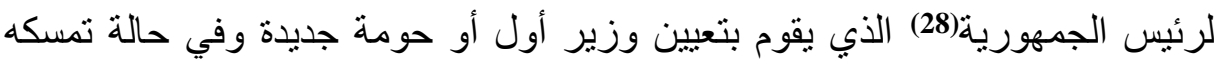
بعدم المو افقة على مخطط عمل الحكومة يتعرض هذا المجلس للحل الوجوبي (29).

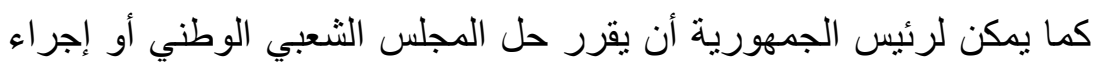

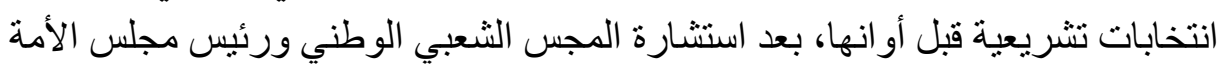
و الوزير الأول، وتجري هذه الانتخابات في كلتا الحالتين في اجل أقصاه ثناثة أنثهر (30). خاتمة: في ختام هذه الورقة البحثية، أمكننا التوصل إلى مجموعة من النتائج التي من أهمها: ـ أنالأنظمة السياسية المعاصرة تقوم على أساس مبدأ الفصل بين السلطات،

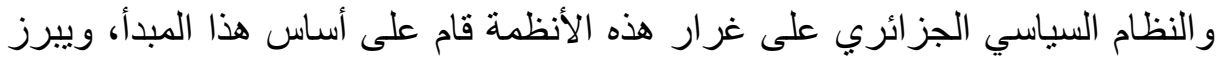

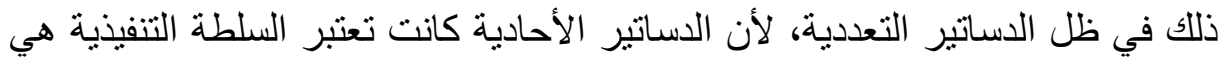

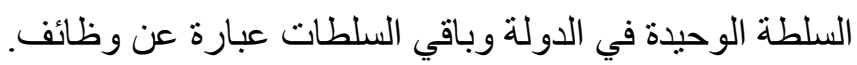

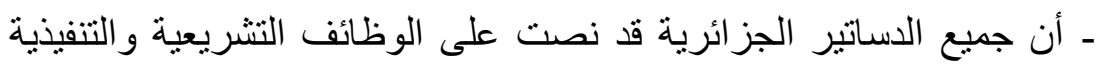

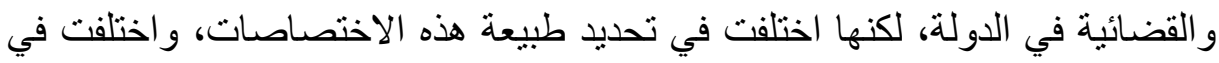

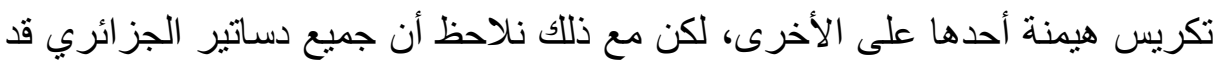

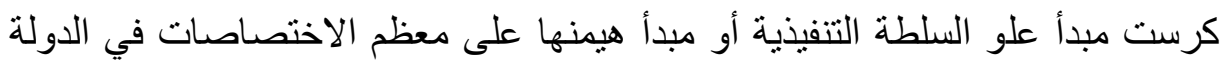
من خلال تدخلها في عمل السلطتين التشريعية و القضائية.

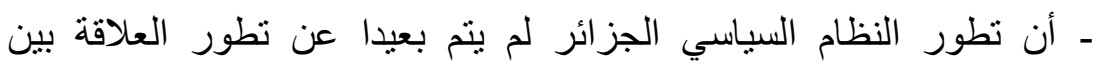

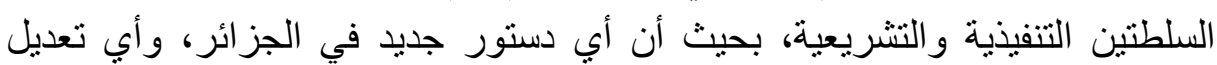


دستوري، لم يتم إلا من خلال المساس بالمواد الناظمة للسلطتين التشريعية والتنفيذية و التشريعية، وهو ما جعل النظام السياسي الجزائري ــعلى غرار العديد من الأنظمة العادية السياسية المعاصرة-مرتبط أساسا بالعلاقة القائمة بين هاتين النئن السلتين.

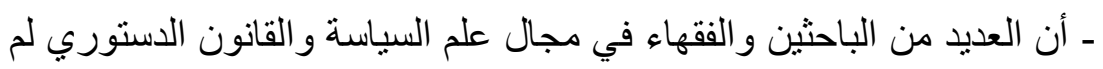

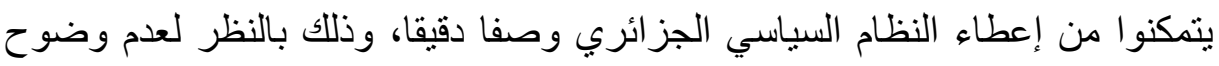

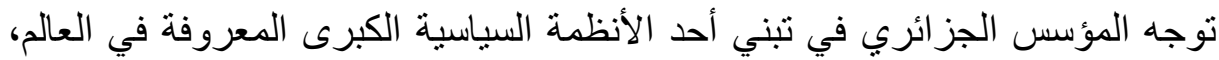
وذلك بالنظر لكونه تبنى نظام المجلسين في السلطة التشريعية من جهة ونظة ونظام الثنائية

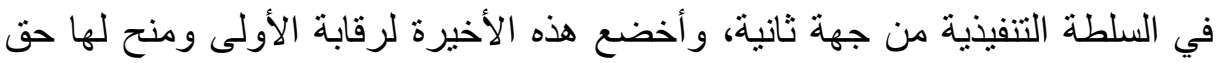

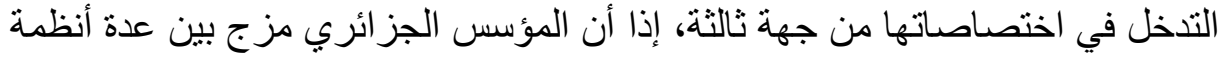
سياسية ولم يأخذ بأحدها.

• و على هذا الأساس نصل في ختام هذه الورقة البحثية إلى أن طبيعة النظام

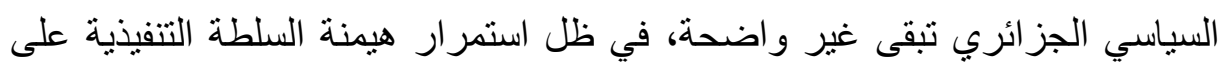
السلطة التشريعية، وهو ما يجعلنا نعتقد بضرورة تيرة تقييد هذه الأخيرة في مقابل توسيع

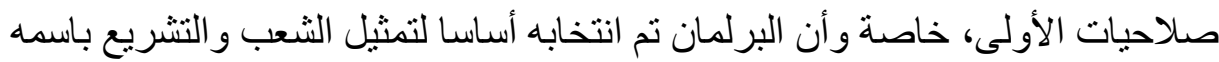
ورقابة الحكومة بدلا منه. الـهو امش:

(1) - ماجد راغب الحلو، النظم السياسية والقانون الدستوري، منشأة المعارف، الاسكندرية، 2005، ص 138.

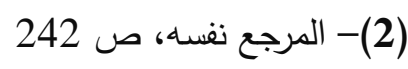
(3) - إبراهيم عبد العزيز شيحا، مبادئ الأنظمة السياسية 》الدول والحكوماته، دار الجامعة الجديدة، 1972، ص ص إن 235. (4) - أحمد وافي-بوكرا إدري، النظرية العامة للدولة والنظام السياسي الجزائري في ظل

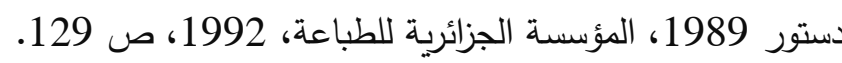
(5) - نعمان أحمد الخطيب، الوسيط في القانون الدستوري، دار الثقافة، الأردن، ط01، صلة

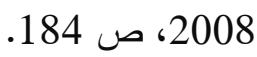
(6)- عمار عباس، العلاقة بين السلطات في الأنظمة السياسية المعاصرة وفي النظام السياسي الجزائري، دار الخلدونية، الجزائر ، ط010، 2010، 2010، ص 26.

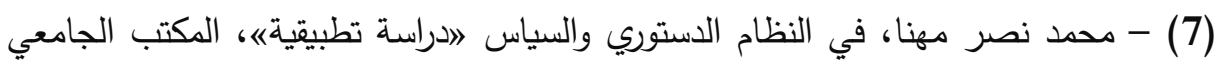

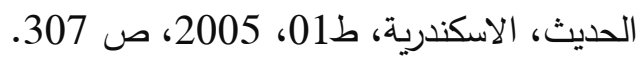

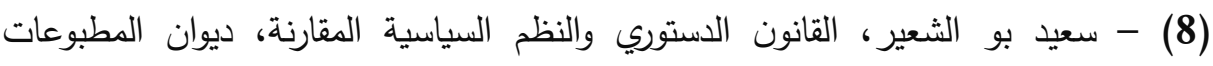

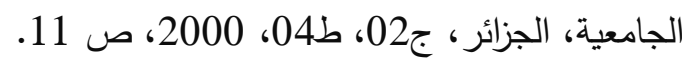

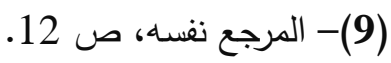
(10) - علي صادق أبو هيف، القانون الدبلوماسي والقنصلي، منشأة المعارف، الاسكندرية، 1961، ص 42 
(11) - حسين عثمان محمد عضمان، النظم السياسية، منشورات الحلبي الحقوقية، لبنان،

$$
\text { 2009، ص } 350 .
$$

(12)- محمد نصر مهنا، مرجع سابق، ص 295 (13)

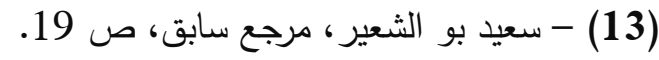

20

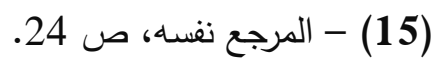

(16) - سعاد بن سرية، مركز رئيس الجمهورية في تعديل 2008، دار بلقيس، الجزائر، 2010، ص 130

(17) - نزيه رغد، الأنظمة السياسية، المؤسسة الحديثة للكتاب، بيروت، ط012، 2012، ص

(18) - نزيه رعد، مرجع سابق، ص 127 - (19)

(19)- ميلود ذبيح، الفصل بين السلطات في التجربة الدستورية الجزائرية، دار الهدى، رئ،

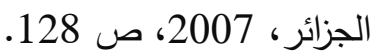

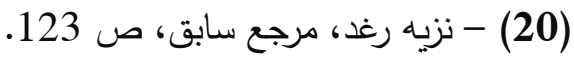

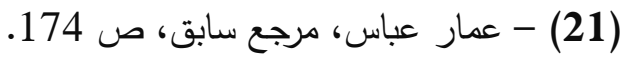
(22) - بن حمودة ليلى، الديمقراطية ودولة القانون، دار هومه، الجزائر، 2014، صداف، ص 89 -

$$
\text { (23) - عباس عمار ، مرجع سابق، ص 179-180. }
$$

(24) - سعدى محمد الخطيب، حقوق الإنسان وضماناتها الدستورية، في اثني وعشرين دولة

عربية 》دراسة مقارنة《، منشورات الحلبي الحقوقية، لبنان، ط01، 2007، ص 180. (25) - غانم عبد دهش عطية الكرعاوي، تنظيم الاختصاصات الدستورية في نظام الثنائية البرلمانية 》دراسة مقارنةه، المركز العربي للدراسات والبحوث العلمية للنشر والتوزيع، القاهرة، ط10، 2017، ص 225.

$$
\text { (26) - عمار عباس، مرجع سابق، ص صن } 127 \text { (27) }
$$

(27) - المادة 79 من دستور الجمهورية الجزائرية الديمقراطية الثعبية لسنة 1996 المعدل

(28) - المادة 81 من دستور الجمهورية الجزائرية الديمقراطية الثعبية لسنة 1996 المعدل

(29) - المادة 82 من دستور الجمهورية الجزائرية الديمقراطية الشعبية لسنة 1996 المعدل

(30) - المادة 129 من دستور الجمهورية الجزائرية الديمقراطية الشعبية لسنة 1996 المعدل 